\title{
A topical cream containing glucosamine and chondroitin sulphate reduced joint pain in osteoarthritis of the knee
}

\author{
Cohen $M$, Wolfe $R$, Mai T, et al. A randomized, double blind, placebo controlled trial of a topical cream containing \\ glucosamine sulfate, chondroitin sulfate, and camphor for osteoarthritis of the knee.J Rheumatol 2003;30:523-8.

\section{QUESTION: In patients with osteoarthritis of the knee, is a topical cream containing glucosamine sulphate, chondroitin sulphate, and camphor more effective than placebo for relieving joint pain?}

\section{Design}

Randomised (allocation concealed*), blinded (patients, healthcare providers, and data collectors)*, controlled trial with 8 weeks of follow up.

\section{Setting}

An outpatient clinic at Monash Medical Center, Australia.

\section{Patients}

63 patients with objectively documented osteoarthritis of the knee who had had knee pain rated $>4 \mathrm{~cm}$ on a 10 $\mathrm{cm}$ visual analogue scale in one or both knees for $>4$ weeks. Exclusion criteria included women of childbearing age who were not using contraception or were pregnant, and patients who had a regular requirement for analgesia for conditions unrelated to osteoarthritis or had used oral or topical glucosamine in the previous 6 weeks. Follow up was $94 \%$ (mean age 63 y, $54 \%$ women).

\section{Intervention}

Patients were allocated to a topical glucosamine/ chondroitin preparation $(n=32)$ or placebo $(n=31)$, to be used as required for 8 weeks. The glucosamine/ chondroitin preparation was a water soluble cream containing glucosamine sulphate $\{3.0 \mathrm{mg} / \mathrm{g}\}\rceil$, chondroitin sulphate $\{7.2 \mathrm{mg} / \mathrm{g}\} \dagger$, and shark cartilage $\{14 \mathrm{mg} / \mathrm{g}\} \dagger$, of which $10-30 \%$ is chondroitin sulphate, camphor (32 $\mathrm{mg} / \mathrm{g})$, and scented with peppermint oil $(9 \mathrm{mg} / \mathrm{g})$. The placebo preparation was a simple cosmetic cream containing conventional skin emollients, petrolatum and mineral oil, conventional emulsifiers, stearic acid and glycerol stearate, and a lesser amount of peppermint oil.

\section{Main outcome measures}

The main outcome was pain rating by patients based on a $10 \mathrm{~cm}$ visual analogue scale that was assessed in the clinic at 0,4 , and 8 weeks. Secondary outcomes included joint pain, stiffness, and a measure of physical function
Sources of funding: Nutrasense Australia Pty, Ltd. and Smart Science Laboratories Inc.

For correspondence: University, Bundoora, Victoria, Australia. marc.cohen@rmit.edu.au Prof $M$ Cohen, RMIT using the Western Ontario and McMaster Universities Osteoarthritis Index and quality of life measured by the Short Form-36 questionnaire.

\section{Main results}

Analysis was by intention to treat. At 4 and 8 weeks, reduction in pain was greater in the glucosamine/ chondroitin preparation group than in the placebo group (table). The groups did not differ for any other outcomes.

\section{Conclusion}

In patients with osteoarthritis of the knee, a topical cream containing glucosamine sulphate, chondroitin sulphate, and camphor was more effective than placebo for relieving joint pain.

*See glossary.

†Information provided by author.

\section{COMMENTARY}

The double blind, placebo controlled trial by Cohen $e t a l$ is one of the first studies performed with adequate methodology to show that topical application of glucosamine and chondroitin sulphate is effective at relieving symptoms from osteoarthritis of the knee. Both chondroitin sulphate and glucosamine sulphate are major components of the extracellular matrix of many connective tissues including cartilage. They act as a preferred substrate for the biosynthesis of glycosaminoglycan chains and, subsequently, for the production of aggrecan and other proteoglycans in cartilage.

Two previous independent studies ${ }^{1-2}$ have shown that glucosamine sulphate was able to act both on symptoms and structure modifications observed in osteoarthritic knee joints. The current study is the first, however, to use a double blind, placebo controlled study design for the evaluation of a topical cream containing glucosamine sulphate, chondroitin sulphate, and camphor. The 8 week trial period included the 4 weeks needed to observe the onset of action of the topical cream. The statistical significance observed for the difference in pain reduction between the glucosamine/chondroitin preparation and placebo groups (visual analogue scale measurements) after 4 weeks remained significant after 8 weeks. Unfortunately, the effects observed on measures of physical function (Western Ontario and McMaster Universities Osteoarthritis Index) and quality of life (Short Form-36 questionnaire) were less striking than the one assessed by the visual analogue scale pain score.

Although this study is of relatively limited size (63 patients), it shows that topical preparations can be of substantial benefit in the management of symptoms of osteoarthritis of the knee. Because the difference observed between the glucosamine/ chondroitin preparation and placebo groups was clinically relevant, these preparations can be particularly helpful in patients who cannot tolerate analgesics or non-steroidal antiinflammatory drugs to manage their symptoms. This study adds to the body of evidence that topical chondroitin sulphate and glucosamine sulphate should be positively considered for the symptomatic management of osteoarthritis.

Jean-Yves Reginster, MD, PhD University of Liege, Liege, Belgium

A topical cream containing glucosamine sulphate, chondroitin sulphate, and camphor v placebo in osteoarthritis of the knee at 8 weeks $\ddagger$

\begin{tabular}{lllll} 
Outcome & Follow up & $\begin{array}{l}\text { Active } \\
\text { cream }\end{array}$ & Placebo & $\begin{array}{l}\text { Difference between } \\
\text { groups }(95 \% \mathrm{CI})\end{array}$ \\
\hline $\begin{array}{l}\text { Mean change from } \\
\text { baseline in joint pain } \\
\text { (visual analogue scale } \\
0-10 \mathrm{~cm})\end{array}$ & Week 4 & -2.6 & -1.4 & $1.2(0.1$ to 2.4$)$ \\
\cline { 2 - 6 } & Week 8 & -3.3 & -1.6 & $1.8(0.6$ to 2.9) \\
\hline
\end{tabular}

1 Reginster JY, Deroisy R, Rovati LC, et al. Long-term effects of glucosamine sulfate on osteoarthritis progression: a randomised, placebo-controlled clinical trial. Lancet 2001;357:251-6. use and delay of progression of knee osteoarthritis: a 3-year, randomized, placebo-controlled, double-blind study. Arch Intern Med 2002;162:2113-23.
2 Pavelka K, Gatterova J, Olejarova M, et al. Glucosamine sulfate

$\neq \mathrm{Cl}$ defined in glossary. 